\title{
When Parallel Worlds Converge
}

\author{
Jeffrey $G$. Wong, MD, FACP \\ General Internal Medicine and Geriatrics, Medical University of South Carolina, Charleston, SC, USA.
}

He was 26 years old and was my first patient.

I was a 23 year old medical student on my surgical clerkship.

He never knew his father. At age 16, he dropped out of school, left home and tried to "make it on the streets".

At age 16, I was taking Driver's Ed and was preparing for a high school debate tournament on the topic: "Resolved: The American criminal justice system should be significantly reformed."

At age 17, he had his first run-in with the criminal justice system for a shoplifting infraction at a convenience market. The charges were ultimately dropped. Over the next several years, he was in and out of jail, detention centers and the like, until at age 21, he was incarcerated in the State Penitentiary for "Assault with a deadly weapon".

At age 17, I had my first run-in with the criminal justice system for a shoplifting infraction at the college bookstore. The charges were ultimately dropped. Over the next several years, I was in and out of different career choices until, at the age of 21, I graduated pre-med with a degree in Human Biology.

Earlier that year in the spring, he began having some pain in his mid-abdomen. He had "used" a similar "ploy" in the past to try to get out of doing undesirable tasks in the prison and so no one paid him much attention - until one day in late June he passed a bowel movement entirely comprised of blood.

Earlier that year in the spring, I began having some pain in my mid-abdomen, possibly related to stress during my preparation for Step 1 of the National Board examination. The pain ultimately passed one day in late June after the examination was over.
He was sent to the surgical ward at the University Hospital where a colonoscopy revealed a 12-cm fungating mass located near the splenic flexure of his transverse colon. The biopsy revealed mucinocystic adenocarcinoma and the abdominal CT scan demonstrated extensive metastatic spread. He was admitted to the surgical service where he underwent subtotal colectomy to relieve his impending bowel obstruction.

I was sent to the surgical ward at the University Hospital for my surgical clerkship rotation. From him, I learned about colostomy wounds, colostomy bags and skin-breakdown. I learned how to put in a central line and how to write TPN orders. I learned about liver failure, ascites, chronic pain, morphine drips, and palliation. I learned how important it is to really talk with your patient, to try to offer comfort, and to try to explain the limits of medical science.

I learned to care.

I also learned that life can be unfair.

Two days before the rotation ended, he fell into a coma.

Two days before the rotation ended, I took the surgical clerkship examination.

Two days later, we both left the service.

Corresponding Author: Jeffrey G. Wong, MD, FACP, General Internal Medicine and Geriatrics, Medical University of South Carolina, 135 Cannon Street, Suite 403K, Charleston, SC 29425, USA (e-mail: wong@musc.edu).

J Gen Intern Med 28(11):1532

DOI: $10.1007 / \mathrm{s} 11606-013-2511-4$

( ) Society of General Internal Medicine 2013

Published online June 8, 2013 